\title{
IE - CEPA : ANALISIS MANFAAT DAN DAMPAK BAGI PERIKANAN INDONESIA
}

\author{
Armen Zulham dan Rani Hafsaridewi \\ Balai Besar Penelitian Sosial Ekonomi Kelautan dan Perikanan, \\ Jalan K.S Tubun Petamburan VI, Jakarta 10260
}

Diterima 28 Oktober 2011 - Disetujui 11 Desember 2011

\begin{abstract}
ABSTRAK
Indonesia - EFTA Comprehensive Economic Partnership Agreement (IE-CEPA) adalah bentuk kerjasama perdagangan Indonesia dengan empat negara EFTA (Islandia, Liechtenstein, Norwegia, dan Swiss) untuk mendorong pertumbuhan ekonomi. Secara politis, kerjasama ini mempunyai arti strategis untuk memperluas pasar, karena nilai transaksi barang dan jasa negara EFTA berperan penting dalam perdagangan dunia. Kajian ini disusun dengan memanfaatkan data sekunder dan publikasi yang ada guna menelaah manfaat kerjasama perdagangan tersebut dalam pengembangan industri perikanan Indonesia. Hasil telaahan menunjukkan manfaat kerjasama tersebut masih memerlukan negosiasi yang kuat, karena dua negara EFTA (Islandia dan Norwegia) merupakan negara perikanan dan memiliki teknologi yang relatif maju. Dua negara EFTA lainnya merupakan jalan untuk memperluas pasar bagi produk perikanan Indonesia, serta mendorong dan meningkatkan investasi Perikanan. Indonesia perlu merintis penerapan rule of origin untuk kelangsungan perdagangan perikanan Indonesia dalam perdagangan global. Indonesia harus meningkatkan kapasitas sumberdaya manusia untuk memperkuat kerjasama tersebut serta mencegah perdagangan ikan yang tidak fair karena hasil transhipment, hasil tangkapan illegal dan re-ekspor ke Indonesia.
\end{abstract}

Kata Kunci: kerjasama perikanan, IE-CEPA, industri perikanan, perdagangan

\section{Abstract: IE-CEPA: Benefit and Impact for Indonesia's Fisheries. By: Armen Zulham and Rani Hafsaridewi}

Indonesia - EFTA Comprehensive Economic Partnership Agreement (IE-CEPA) is a trade cooperation between Indonesia and EFTA countries (Iceland, Liechtenstein, Norway and Switzerland) to support the economic growth. From Indonesia political point of view, this trade cooperation has a strategic position for market access due to the EFTA countries play important roles in global commodities and services trading. This analysis used the secondary data and published literatures to analysis impacts and benefits of this trade cooperation for fisheries development in Indonesia. Result of the analysis suggested that Indonesia still need to strengthen its negotiation due to the advanced stage of fishing technology from two EFTA countries (Iceland and Norway). Other two EFTA members are potential market access for Indonesian fish products. Indonesia has to implement rule of origin for sustainable fish trade to increase fish investment and increase completion in global market. Indonesia must improve its human capacity building to strengthen its position in this trade cooperation and prevent unfair fish trade due to trans-shipment, illegal fishing and re-export fish to Indonesia.

Keywords: fisheries collaboration, IE-CEPA, fisheries industries, trade 


\section{PENDAHULUAN}

European Free Trade Association (EFTA) merupakan blok alternatif bagi negaranegara Eropa yang tidak tergabung dalam negara Uni Eropa (European Union - EU) yang dibentuk pada tanggal 3 Mei 1960. Pada Tahun 1970, Islandia bergabung dengan EFTA dan kemudian diikuti oleh negara Liechtenstein pada tahun 1991. Saat ini negara yang tergabung dalam EFTA terdiri dari 4 negara yaitu: Islandia, Liechtenstein, Norwegia, dan Swiss (Anonimous, 2011c).

Peranan Negara-negara EFTA tidak dapat diabaikan dalam perdagangan dunia, karena nilai transaksi perdagangan barang dan jasa masing-masing berada pada urutan ke 9 , dan ke 5 dalam perdagangan dunia. Secara politis Indonesia melihat negaranegara EFTA mempunyai arti strategis dalam pembangunan ekonomi, yaitu: untuk meningkatkan kapasitas perdagangan dan mendorong investasi perikanan di Indonesia. Pada sisi lain diharapkan akan berdampak untuk mendorong perluasan kesempatan kerja, mempercepat transfer teknologi dan memperbaiki kualitas lingkungan.

Secara politis kunjungan kenegaraan Presiden Switzerland selaku ketua Dewan EFTA ke Indonesia dari tanggal 5-9 Juli 2010 telah mereformulasi perjanjian kerjasama Comprehensive EFTA - Indonesia Free Trade Agreement (CEITA) menjadi perjanjian Indonesia - EFTA Comprehensive Economic Partnership Agreement (IE-CEPA). Hal ini disebabkan karena negara-negara yang bekerjasama tersebut memiliki karakteristik potensi sumberdaya dan ekonomi yang berbeda satu dengan lainnya. Kerjasama tesebut diarahkan untuk mengembangkan kemitraan ekonomi secara menyeluruh dari semua sektor yang terkait dengan perdagangan dan investasi secara teknis dan kelembagaan (Anonimous, 2011d).

Perikanan Indonesia merupakan salah satu sektor yang terkait dengan kerjasama tersebut. Upaya yang dilakukan agar sektor perikanan dapat memperoleh manfaat dari kerjasama tersebut, maka sektor ini harus mengetahui potensi pasar perikanan pada keempat negara EFTA tersebut, serta mempelajari peluang investasi dan transfer teknologi dari negara EFTA ke Indonesia. Demikian juga sebaliknya negara EFTA sebagai mitra akan melihat peluang pasar di Indonesia, serta investasi dan teknologi yang diperlukan dalam pengembangan perikanan Indonesia. Tujuan dari tulisan ini adalah untuk memperoleh informasi tentang strategi atau langkah-langkah yang diperlukan oleh sektor kelautan dan perikanan Indonesia terhadap kesepakatan kerjasama IE-CEPA.

\section{METODOLOGI}

\section{Kerangka Pemikiran}

Dalam cakupan kerjasama Indonesia EFTA, maka keikutsertaan sektor perikanan menjadi penting karena perikanan merupakan salah satu sektor yang memberi kontribusi dalam pertumbuhan ekonomi Indonesia. Catatan menunjukkan kontribusi sektor perikanan dalam PDRB nasional sekitar 2,5\% per tahun. Sektor perikanan perlu memanfaatkan kerjasama IE-CEPA dalam memperoleh informasi untuk:

1. Mendapat strategi perluasan akses pasar produk perikanan.

2. Mendorong investasi perikanan di Indonesia.

3. Mendorong implementasi rule of origin produk perikanan untuk menjamin perdagangan yang fair.

4. Memanfaatkan kemitraan ekonomi tersebut dalam meningkatkan kapasitas sumberdaya manusia sehingga produk Indonesia dapat masuk ke pasar EFTA khususnya dan Uni Eropa pada umumnya.

\section{Pendekatan}

Dalam rangka menjawab tujuan yang telah diuraikan di atas dan informasi dari kerangka pikir tersebut, maka tulisan ini memanfaatkan dua sumber utama yaitu:

1. Data sekunder yang diterbitkan oleh Badan Pusat Statistik, terutama tentang keragaan 
ekspor dan impor produk perikanan Indonesia.

2. Hasil studi perdagangan yang terkait dengan EFTA, potensi ekonomi negara EFTA dan peluang pasar di negara tersebut yang telah dipublikasikan.

\section{Analisis Data}

Data dan informasi yang diperoleh disusun dengan tabulasi statistik sederhana. Data dan informasi tersebut dianalisis secara deskriptif untuk menjelaskan fenomena dan karakteristik perekonomian dari negara EFTA. Analisis tersebut dikaitkan dengan peluang sektor perikanan Indonesia memasuki pasar negara EFTA serta investasi EFTA yang dapat mendorong industri perikanan Indonesia.

\section{NERACA PERDAGANGAN INDONESIA - EFTA}

Pada tahun 2010 total perdagangan antara Indonesia dengan negara-negara EFTA tercatat sebesar US\$ 1 milyar, terdiri dari ekspor senilai US\$ 232 juta dan impor sebesar US\$ 769 juta. Angka ini menurun sebesar 30,48\% bila dibandingkan dengan tahun 2009. Total perdagangan antara Indonesia dengan negaranegara EFTA pada periode Januari-Februari 2011 adalah sekitar US\$140 juta, atau terjadi penurunan sebesar $26,91 \%$ bila dibandingkan dengan periode yang sama pada tahun 2010 yakni sebesar US\$ 191 juta.

Nilai perdagangan Indonesia dengan negara - Negara EFTA menunjukkan gejala defisit (Tabel 1). Selama Januari - Februari 2011, nilai ekspor Indonesia ke negara EFTA mencapai 23 Juta US \$ sedangkan impor Indonesia dari negara EFTA sekitar US \$ 118 Juta.

Ekspor Indonesia ke negara-negara EFTA umumnya adalah produk primer, sedangkan impor Indonesia dari negara EFTA merupakan barang-barang hasil industri dan bahan baku untuk industri. Perdagangan Indonesia dengan EFTA mencakup beberapa negara yaitu: Swiss, Norwegia, Islandia, dan Liechtenstein.

\section{(1) Indonesia - Swiss}

Perekonomian Swiss ditopang oleh tiga sektor utama, yaitu: pertanian (landwirtschaft), industri (Industrie), dan jasa (dienstleistungen). Jumlah penduduk Swiss sekitar 7,8 Juta jiwa, dari jumlah tersebut sekitar $22 \%$ merupakan warga asing. Penduduk Swiss yang bekerja pada sektor pertanian sekitar $10 \%$ sehingga sektor ini diproteksi oleh pemerintah, $40 \%$ bekerja pada industri dan kerajinan (seperti industri mesin dan logam, industri jam, industri tekstil), dan $50 \%$ bekerja pada industri jasa.

Pada periode Januari - Februari 2011 ekspor utama Indonesia ke Swiss di dominasi oleh batubara, pakaian jadi, minyak atsiri, kopi, udang beku, kepiting dan kerang-kerangan. Data BPS Tahun 2011 (Anonimous, 2011a) menunjukkan bahwa nilai ekspor Indonesia ke Swiss adalah sekitar US \$ 11 juta yang berasal dari batubara (17\%), pakaian jadi $(22 \%)$, minyak atsiri $(9 \%)$, kopi $(5 \%)$, udang

Tabel 1. Nilai Perdagangan Indonesia - EFTA sampai dengan Februari 2011.

Table 1. Value of Trade Between Indonesia - EFTA until February 2011.

\begin{tabular}{|c|c|c|c|}
\hline No & Negara/ Country & $\begin{array}{l}\text { Nilai Ekspor (FOB - US\$)/ } \\
\text { The Export Value (FOB - US\$) }\end{array}$ & $\begin{array}{c}\text { Nilai Impor (CIF - US \$)/ } \\
\text { The Import Value (CIF - US\$) }\end{array}$ \\
\hline 1 & Swiss & $11,019,284(50.5 \%)$ & $83,459,888(70.69 \%)$ \\
\hline 2 & Norwegia & $10,611,928$ (48.61\%) & $34,158,141(28.93 \%)$ \\
\hline 3 & Islandia & 201,188 (0.92\%) & $453,221(0.38 \%)$ \\
\hline \multirow[t]{2}{*}{4} & Liechtenstein & $0(0 \%)$ & $49(0 \%)$ \\
\hline & TOTAL & $21,832,400(100 \%)$ & $118,071,299(100 \%)$ \\
\hline
\end{tabular}

Sumber : Diolah dari Buletin Statistik Perdagangan Luar Negeri Februari 2011.

Source : Foreign Trade Statistical Bulletin, February 2011 (Processed). 
beku $(0,8 \%)$, kepiting dan kerang-kerangan $(1,42 \%)$, barang dari karet $(2,4 \%)$, alas kaki $(6,8 \%)$. Pada periode yang sama, nilai impor Indonesia dari Swiss mencapai US\$ 83,5 juta yang mencakup mesin dan peralatan yang berpresisi tinggi serta bahan pelengkap industri manufaktur di Indonesia.

Mitra ekspor utama Swiss adalah Jerman (20\%), Amerika Serikat $(9,4 \%)$, Italy $(8,8 \%)$, Perancis (8,6\%), Inggris (4,7\%), Spanyol (3,5\%), Belanda (3\%). Di samping itu mitra impor Swiss adalah Jerman $(34,7 \%)$, US $(5,1 \%)$, Italy $(11,4 \%)$, Perancis $(9,7 \%)$, Inggris (3,2\%), Austria $(4,2 \%)$, Belanda $(4,8 \%)$.

\section{(2) Indonesia - Norwegia}

Jumlah penduduk Norwegia sekitar 4,9 juta orang. Perekonomian Norwegia sangat tergantung pada industri perminyakan dan gas alam. Untuk mengatasi ketergantungan pada sektor minyak dan gas alam, maka Norwegia mengembangkan industri pengolahan pangan, industri perkapalan, industri pulp dan kertas, industri logam, industri kimia, pertambangan, kehutanan, tekstil dan perikanan (Lexmon, 2007).

Pada periode Januari - Februari 2011, nilai ekspor Indonesia ke Norwegia mencapai US\$ 10,6 juta. Nilai ekspor tersebut didominasi oleh kayu olahan $(6,4 \%)$, pakaian jadi $(14,3 \%)$, tekstil $(3,6 \%)$, barang dari karet $(1,12 \%)$, asam lemak $(13,65 \%)$, alat fotografi dan optik $(5,4 \%)$, buah dan sayur olahan $(3,61 \%)$, mebel dari rotan (10,5\%), mebel dari bahan lainnya $(10,9 \%)$, damar tiruan dan bahan dari plastik $(3,8 \%)$, alaskaki $(4,9 \%)$, produk keramik $(1,6 \%)$, suku cadang mesin industri $(14,5 \%)$. Pada sisi lain komoditas perikanan yang diekspor ke Norwegia terdiri dari ubur-ubur, kepiting, ikan dan kerang-kerangan sekitar 0,015\% dari nilai ekspor tersebut (Anonimous, 2011a). Pada periode yang sama, impor Indonesia dari Norwegia mencapai US \$ 34,2 juta (Anonimous, 2011b). Nilai impor tersebut terdiri dari fertilizer manufactured $(23,2 \%)$, peralatan listrik $(15,7 \%)$, peralatan handling dan onderdilnya $(10,4 \%)$, material dari karet $(9,9 \%)$, bubur kertas $(7,3 \%)$.
Dalam perdagangan global mitra utama pasar ekspor Norwegia adalah Denmark dan Swedia (9,9\%), Jerman (12,8\%), Ingris 26,9\%, Amerika Serikat (7,3\%). Impor Norwegia bersumber dari Denmark dan Swedia (21,2\%), Jerman (13,4\%), Inggris (6\%), Amerika Serikat $8,7 \%$.

\section{(3) Indonesia - Islandia}

Perekenomian Islandia sekitar 5,5\% tergantung pada sektor pertanian, $24,7 \%$ pada industri manufaktur dan 69,9\% tergantung pada industri jasa. Dengan jumlah penduduk Islandia sekitar 318,5 ribu jiwa, maka penduduk Islandia saat ini banyak bekerja pada sektor industri manufaktur dan industri jasa yang menopang perekonomian negara tersebut. Industri perikanan di Islandia didukung oleh bank (Islandbanki), sehingga cukup berkembang. Loan untuk seafood Industri mencapai $12 \%$ dari total loan yang disalurkan oleh Islandbanki. Industri perikanan di Islandia dikembangkan melalui perusahaan komersial, saat ini terdapat sekitar 50 perusahaan komersial (perusahaan tersebut beroperasi sesuai kuota yang ditetapkan oleh pemerintah). Kontribusi seafood industri terhadap GDP Islandia rata-rata mencapai $8 \%$ setiap tahun, hal ini menunjukkan pentingnya peran industri perikanan di Islandia (Björnsson, 2010).

Total nilai ekspor Indonesia ke Islandia pada periode Januari - Februari 2011 sekitar US \$ 201 juta (0,92\% dari nilai ekspor Indonesia ke negara-negara EFTA). Komoditas yang diekspor sangat terbatas meliputi: barang dari karet dan barang dari rotan. Nilai ekspor barang dari karet dan barang dari rotan mencapai masing-masing mencapai $93,7 \%$ dan $4,4 \%$ dari nilai total ekspor Indonesia ke Islandia (Anonimous, 2011a).

Nilai impor Indonesia dari Islandia pada periode tersebut sekitar US\$ 453,2 ribu. Barang yang diimpor dari Islandia meliputi: pig iron, spiegelesein, sponge iron, dan ferro-alloys; minyak hewan dan lemak; articles of apparel; parts and accessories of the motor vehicles (Anonimous, 2011b). Nilai impor dari pig Iron, 
spiegelesein, sponge iron, and ferro-alloys; animal oils and fats; articles of apparel; dan parts and accessories of the motor vehicles masing-masing mencapai 86,1\%, 11,4\% dan $1,3 \%$ dari total nilai impor Indonesia dari Islandia. Barang yang diimpor tersebut merupakan bahan baku untuk industri dalam negeri.

Perlu dicatat, perekonomian Islandia tergantung pada industri perikanan, industri pemurnian alumunium, industri ferosilicon, perangkat lunak, barang dari wol, dan pariwisata. Nilai ekspor Islandia mencapai US\$ 4.766 milyar, pasar ekspor Islandia adalah negara-negara Uni Eropa (58,9\%), Inggris (14\%), Amerika Serikat $(5,6 \%)$ dan Jepang (4,5\%). Sedangkan impor Islandia sebesar US\$ 6.175 billion terdiri dari peralatan dan mesin, petrolium products, bahan baku untuk makanan, dan pakaian. Islandia mengimpor kebutuhannya dari negara-negara Masyarakat Ekonomi Eropa (32,7\%), Amerika serikat $(14,4 \%)$, Swedia $(10,7 \%)$, Denmark $(8,4 \%)$, Inggris (5,7\%), Cina (5,4\%), Jepang (5\%) dan Norwegia $(4,9 \%)$.

Pada tahun 2010 Islandia mengimpor bahan baku ikan untuk industri pengolahan ikannya yang mencapai sekitar 80,8 ribu ton, jumlah ini diperkirakan akan meningkat seiring dengan semakin berkurangnya potensi ikan di perairan laut Utara karena kelebihan effort. Jenis ikan yang di Impor meliputi cod, saith, catfish, spotted catfish, herring (Björnsson, 2010).

\section{(4) Indonesia - Liechtenstein}

Liechtenstein merupakan negara kecil yang berada antara Swiss dengan Austria dengan luas areal $160.475 \mathrm{Km}^{2}$. Jumlah penduduk negara tersebut sekitar 36 ribu jiwa. Pendapatan per kapita sekiatar US\$ 134.045 per tahun. Perekonomian negara kecil ini sangat tergantung pada perdagangan dan industri jasa.

Ekspor Indonesia ke Liechtenstein saat ini dapat dikatakan belum ada. Namun impor Indonesia dari Liechtenstein sampai dengan bulan April 2011 mencapai US\$ 40 ribu. Impor tersebut terdiri dari pigmen bahan pewarna cat (mencapai US $\$ 38,4$ ribu): peralatan elektronik dan listrik, logam, bahan rajutan wool buatan tangan dan pabrik.

Pasar ekspor produk Liechtenstein adalah negara-negara Masyarakat Ekonomi Eropa (62,6\%), Swiss (15,7\%), ke berbagai negara lainnya $(21,1 \%)$. Kebutuhan energi Liechtenstein $85 \%$ tergantung pada negara Swiss. Industri yang menopang perekonomian Liechtenstein adalah industri peralatan elektronik, industri logam, dental products, industri keramik, industri pharmasi, industri makanan, industri peralatan presisi, pariwisata, produk pertanian (gandum, barley, jagung, kentang, ternak dan susu).

\section{MEMANFAATKAN PELUANG KERJASAMA}

\section{(1) Akses Pasar}

Kerjasama kemitraan ekonomi dengan negara EFTA bagi sektor perikanan perlu dimanfaatkan dengan baik, karena:

a) Negara-negara EFTA belum memiliki standar produk yang sama diantara mereka, tetapi negara-negara tersebut umumnya mengikuti standarisasi perdagangan barang negara Uni Eropa.

b) Total jumlah penduduk negara-negara EFTA sekitar 13,5 Juta jiwa, dengan pendapatan per kapita yang cukup tinggi US \$ 134.045 per tahun, sehingga kualitas barang yang diperlukan juga cukup tinggi.

c) Industri yang berkembang di negara EFTA, merupakan industri dengan teknologi maju, dan menghasilkan barang dengan presisi tinggi. Sebagian industri tersebut memerlukan bahan baku untuk memenuhi permintaan pasar dengan mutu prima.

Indonesia merupakan pasar potensial untuk barang-barang hasil industri dari negara EFTA, karena jumlah penduduk sebesar 237 juta, Indonesia juga merupakan negara yang sedang membangun sehingga memerlukan berbagai peralatan/barang modal untuk 
menghasilkan barang yang diperdagangkan. Bagi Indonesia untuk memasarkan hasil produksinya ke pasar negara EFTA memerlukan upaya tambahan karena standar mutu barang yang diminta pasar sangat tinggi. Oleh sebab itu bagi Indonesia negosiasi perdagangan sangat diperlukan, karena banyak strategi kebijakan non tarif yang harus rancang.

Analisis parsial perdagangan produk perikanan Indonesia-EFTA yang dilakukan oleh Rahardian dkk (2011) menunjukkan trade creation effect yang positif dan cukup signifikan dengan Norwegia. Komoditas perikanan negara EFTA yang berpeluang masuk ke Indonesia, adalah komoditas trout, rainbow trout, pacific salmon, atlantic salmon, danube salmon, cod. Pada sisi lain komoditas Indonesia adalah: udang, kerang-kerangan dan kepiting. Dengan mempertimbangkan struktur perekonomian Tabel 2, peluang komoditas perikanan Indonesia masuk ke pasar negara EFTA, yang mencakup negara Islandia, Norwegia, Swiss dan Leicstenstein adalah sebagai berikut:

\section{Peluang Pasar di Islandia}

Islandia merupakan negara perikanan dan memiliki industri pengolahan ikan dengan kapasitas yang besar. Negara ini menolak bergabung dengan Negara Masyarakat Eropa, karena akan kehilangan kontrol terhadap sumberdaya ikan dalam yurisdiksi wilayah perairannya. Industri pengolahan ikan di Islandia dilaporkan sering kekurangan pasokan bahan baku secara temporer, karena suplai ikan dari perairan mereka semakin menipis. Hal ini disebabkan karena terjadi ekses kapasitas penangkapan ikan di perairan tersebut dan pengaruh dari kuota penangkapan ikan ${ }^{1}$, sehingga Islandia memerlukan impor ikan dari negara lain (Björnsson, 2010). Walaupun ekspor Indonesia ke Islandia saat ini didominasi oleh barang dari karet dan rotan, namun peluang untuk memasukkan

1 Untuk menjaga kuotanya, armada penangkapan ikan membuang hasil tangkapan ikan yang nilai ekonomisnya rendah di laut dan hanya mendaratkan ikan yang bernilai ekonomis tinggi. produk perikanan memerlukan negosiasi yang kuat, yang mencakup beberapa aspek, yaitu:

a) Negosiasi pertama menyangkut mengisi kekurangan pasokan bahan baku ikan industri pengolah ikan pada kedua negara. Jenis ikan yang diperdagangkan tersebut harus sesuai dengan kebutuhan Industri. Negosiasi tersebut menyangkut kebijakan: jenis dan ukuran ikan, kuota ikan yang diperdagangkan, persyaratan mutu ikan, dan jadwal pengiriman ikan.

b) Negosiasi kedua, mendorong Islandia mempermudah masukknya canning produk perikanan dengan brand Indonesia (terutama ikan kaleng dan kepiting), yang dikaitkan dengan impor lemak hewani Islandia ke Indonesia.

c) Mendorong investasi Islandia di Indonesia untuk mengekstraksi lemak hewani dari ikan dengan memanfaatkan ikan patin untuk mensubtitusi lemak hewani impor di pasar Indonesia.

d) Pada sisi lain, agar investasi UPI Islandia dapat direalisasikan di Indonesia maka UPI tersebut diberi insentif izin pemasukan bahan baku untuk keperluan produksi dan hasilnya di re-ekspor ke pasar tujuan.

\section{Peluang Pasar di Norwegia}

Norwegia merupakan negara yang ekonominya tergantung pada minyak dan gas bumi, namun negara tersebut mengekspor ikan ke negara Eropa lainnya. Akses pasar perikanan Indonesia ke Norwegia dapat diperbesar terutama untuk udang, uburubur, kepiting, ikan dan kerang-kerangan dalam bentuk segar/beku atau olahan. Kompensasi untuk peningkatan pangsa pasar ikan harus dinegosiasikan, satu paket dengan produk makanan dan minuman. Negosiasi ini dikaitkan dengan tingginya kebutuhan komponen mesin industri buatan Norwegia yang masuk ke Indonesia. 
Tabel 2. Struktur Perekonomian dan Produk Ekspor IE-CEPA Tahun 2010. Table 2. Structure of the Economy and Exported Product of IE-CEPA, 2010.

\begin{tabular}{|c|c|c|c|c|c|}
\hline No & $\begin{array}{l}\text { Negara/ } \\
\text { Country } \\
\text { I-EFTA }\end{array}$ & $\begin{array}{l}\text { Jumlah } \\
\text { Penduduk } \\
\text { (Jiwa)/ } \\
\text { Population } \\
\text { (person) }\end{array}$ & $\begin{array}{l}\text { Struktur perekonomian dalam } \\
\text { GDP/ Structure of Economy in } \\
\text { Gross Domestic Product }\end{array}$ & $\begin{array}{c}\text { Pendapatan } \\
\text { per kapita } \\
\text { (US\$/tahun)/ } \\
\text { Income per } \\
\text { Capita (US\$/ } \\
\text { year) }\end{array}$ & $\begin{array}{l}\text { Produk Ekspor/ } \\
\text { Products Exported }\end{array}$ \\
\hline 1 & Indonesia & $237,641,326$ & $\begin{array}{l}\text { Pertaninan/ Agriculture (15\%), } \\
\text { pertambangan dan penggalian/ } \\
\text { mining \& quarrying (11.15\%), } \\
\text { industri pengolahan/ processing } \\
\text { industry ( } 24.82 \%), \\
\text { listrik, gas dan air minum/ } \\
\text { electricity, gas \& water supply } \\
(0.78 \%), \text { kontruksi/ Construction } \\
(10.29 \%), \text { perdagangan, hotel } \\
\text { dan restoran/ trade, hotels } \\
\text { and restaurants (13.72\%), } \\
\text { pengangkutan dan komunikasi/ } \\
\text { transport \& communication } \\
\text { (6.50\%), keuangan dan jasa } \\
\text { perusahaan/ financial \& business } \\
\text { services (7.21\%) }\end{array}$ & 3,004 & $\begin{array}{l}\text { Udang/ Shrimp, kopi/ } \\
\text { coffee, CPO, kakao/ } \\
\text { cocoa, karet dan } \\
\text { produk karet/ rubber } \\
\text { and rubber products, } \\
\text { tekstil dan produk } \\
\text { tekstil/ textiles and } \\
\text { textiles products, } \\
\text { panel elektronika/ } \\
\text { electronics, komponen } \\
\text { kendaraan bermotor/ } \\
\text { motor vehicle } \\
\text { components, furnitur/ } \\
\text { furniture }\end{array}$ \\
\hline 2 & Swiss & $7,866,500$ & $\begin{array}{l}\text { Industri jasa/ Service industry } \\
\text { (73.3\%), industri manufaktur/ } \\
\text { manufacturing industry ( } 25.6 \%) \text {, } \\
\text { industri primer/ primary industry } \\
(1.1 \%)\end{array}$ & 75,835 & $\begin{array}{l}\text { Mesin/machine, bahan } \\
\text { kimia/ chemicals, } \\
\text { logam/ metals, } \\
\text { jam/ watch, produk } \\
\text { pertanian/ agriculture }\end{array}$ \\
\hline 3 & Norwegia & $4,993,100$ & $\begin{array}{l}\text { Pertanian/ Agriculture } \\
(2.2 \%), \text { industri manufaktur/ } \\
\text { manufacturing industry }(21.1 \%), \\
\text { jasa/ services }(76 \%)\end{array}$ & 84,443 & $\begin{array}{l}\text { Minyak bumi dan } \\
\text { produk turunannya/ } \\
\text { petroleum and its } \\
\text { derivatives, peralatan } \\
\text { dan mesin/ equipment } \\
\text { and machinery, logam/ } \\
\text { metals, bahan kimia/ } \\
\text { chemicals, kapal dan } \\
\text { ikan/ ships and fish }\end{array}$ \\
\hline 4 & Islandia & 318,452 & $\begin{array}{l}\text { Pertanian/ Agriculture } \\
\text { (5.9\%), industri manufaktur/ } \\
\text { manufacturing industry (20.6\%), } \\
\text { industri jasa/ services industry } \\
(73.1 \%)\end{array}$ & 39,025 & $\begin{array}{l}\text { Ikan segar dan ikan } \\
\text { olahan/ fresh fish } \\
\text { and fish products, } \\
\text { almunium/alumunium, } \\
\text { produk peternakan/ } \\
\text { livestock products }\end{array}$ \\
\hline 5 & Liecstentein & 36,010 & $\begin{array}{l}\text { Pertanian/ Agriculture } \\
\text { (7.1\%), industri manufaktur/ } \\
\text { manufacturing industry (42.8\%), } \\
\text { industri jasa/ services industry } \\
(50.1 \%)\end{array}$ & 134,045 & $\begin{array}{l}\text { Barang elektronik/ } \\
\text { Electronics products, } \\
\text { barang logam/ metals, } \\
\text { dental produt/ } \\
\text { dental producrs, } \\
\text { keramik/ ceramics, } \\
\text { barang parmasi/ } \\
\text { pharmaceutical goods, } \\
\text { bahan pangan/ food, } \\
\text { peralatan presisi } \\
\text { tinggi/ high-precision } \\
\text { equipment, alat optik/ } \\
\text { optical instrument dan } \\
\text { industri pariwisata/ } \\
\text { tourism industry }\end{array}$ \\
\hline
\end{tabular}

Sumber : Diolah dari berbagai sumber 2011.

Source : Compiled from various sources, 2011. 


\section{Peluang Pasar di Swiss}

Swiss merupakan negara yang perekonomiannya tergantung pada industri jasa dan industri manufaktur. Bahan pangan umumnya diimpor dari luar. Ekspor udang beku, kepiting dan kerang-kerangan dari Indonesia nilainya hanya berkisar antara $0,8 \%-1,42 \%$ dari total nilai ekspor Indonesia ke Swiss. Pangsa pasar Udang, kepiting dan kerang-kerangan beku dan olahan ini dapat ditingkatkan karena kegiatan internasional sering dilakukan di Swiss. Peningkatan pangsa pasar komoditas tersebut dinegosiasikan dengan paket Tekstil dan Produk Tekstil serta produk pertanian lainnya.

\section{Peluang Pasar di Liechtenstein}

Merupakan negara kecil dengan pendapatan per kapita yang tinggi (US \$ 147.000). Perekonomian ditopang oleh industri electronik, industri logam, dental products, ceramics, pharmaceuticals, food products, precision instruments, tourism, optical instruments. Dalam rangka memenuhi konsumsi negara ini mengimpor produk pertanian, bahan baku industri maupun energi, serta makanan dan minuman. Produk perikanan olahan (udang beku, ikan kaleng, kepiting) merupakan produk yang dapat dipasarkan di negara tersebut, karena negara ini terbatas sumberdaya perikanan. Peningkatan ekspor komoditas perikanan tersebut sebagai kompensasi tingginya surplus perdagangan Leictenstein dengan Indonesia.

Berdasarkan hasil telaahan, produk yang diekspor oleh Indonesia ke negara-negara EFTA lebih banyak dalam bentuk produk primer. Sementara impor Indonesia dari negara EFTA didominasi oleh barang modal dan bahan pelengkap untuk Industri cat dan peralatan elektronika serta barang-barang yang terbuat dari wool. Jenis barang dan produk ekspor dan impor Indonesia ke negara EFTA dapat dilihat pada Tabel 3 di bawah ini.

\section{(2) Rule of Origin}

Pada perdagangan internasional pemberitahuan asal barang (rule of origin) merupakan aspek penting yang harus dipertimbangkan untuk menjaga stabilitas harga barang dan keberlanjutan industri di dalam negeri. Indonesia melihat penerapan rule of origin merupakan hal yang penting untuk menjaga kesinambungan perdagangan Indonesian di pasar EFTA.

Dalam implementasinya, dokumen pemberitahuan asal barang tersebut, menetapkan legalitas asal barang yang diimpor. Dokumen ini pada awalnya untuk membantu menetapkan tarif bea masuk barang. Namun saat ini karena sistim perdagangan di dorong ke perdagangan bebas maka, dokumen asal barang tersebut digunakan untuk mengetahui sumber barang, tujuan penggunaan barang impor dan produk yang dihasilkan dari barang impor tersebut, serta tujuan pasar dari produk tersebut.

Pada kesepakatan perdagangan antar negara, dokumen pemberitahuan asal barang tersebut formatnya harus standar dan berisi informasi detail dari barang yang diperdagangkan, sehingga akan diketahui sumber barang yang diimpor apakah dari negara tersebut atau dari sumber lain (transhipment, atau re-ekspor). Standarisasi ini menjadi bagian dari kerjasama tentang kepabeanan, dan kesepakatan internasional lain (seperti: Marine Stewardship Council (MSC), Code of Conduct for Responsible Fisheries, HAACP dan lain sebagainya. Rule of Origin ini menjadi persyaratan penting dalam perdagangan di masa depan (Clarke, 2009).

Perlu dicatat beberapa negara EFTA yang tidak bergabung dengan Uni Eropa menyangkut kebijakan sumberdaya perikanan di pearian negara Eropa dan kebijakan tentang Rule of Origin dalam perdagangan hasil penangkapan ikan. Dengan demikian, terkait dengan uraian di atas, maka upaya Indonesia dalam perdagangan dengan negara EFTA adalah:

a) Mendorong negara EFTA membangun industri pengolahan ikan di Indonesia. Investasi ini dapat direalisasikan melalui dua alternatif. Alternatif pertama industri pengolahan tersebut mengunakan bahan baku impor dan produknya diekspor ke 
Tabel 3. Jenis Barang Ekspor dan Impor Indonesia dan EFTA.

Table 3. Types of Exported and Imported Products Between Indonesia and EFTA Countries.

\begin{tabular}{|c|c|c|c|}
\hline \multirow[b]{2}{*}{ No } & \multirow{2}{*}{$\begin{array}{l}\text { Negara/ } \\
\text { Country }\end{array}$} & \multicolumn{2}{|c|}{ Jenis Barang/ Types of Goods } \\
\hline & & $\begin{array}{l}\text { Ekspor dari Indonesia/ } \\
\text { Export from Indonesia }\end{array}$ & $\begin{array}{c}\text { Impor Indonesia/ } \\
\text { Import From Indonesia }\end{array}$ \\
\hline 1 & Swiss & $\begin{array}{l}\text { Batubara/Coals (17\%), pakaian jadi/ } \\
\text { clothing ( } 22 \%), \text { minyak atsiri/ essential } \\
\text { oils }(9 \%) \text {, kopi/ coffee }(5 \%) \text {, udang } \\
\text { beku/ frozen shrimp }(0.8 \%) \text {, kepiting } \\
\text { dan kerang-kerangan/ crabs and } \\
\text { shellfish }(1.42 \%) \text {, barang dari karet/ } \\
\text { rubber products ( } 2.4 \%) \text {, alas kaki/ } \\
\text { footwear }(6.8 \%) \text {. }\end{array}$ & $\begin{array}{l}\text { mesin tekstil dan kulit serta } \\
\text { onderdilnya/ textile and rubber } \\
\text { machinery \& its spare parts (14.6\%); } \\
\text { mesin dan onderdil bukan listrik/ } \\
\text { machinery and non-electrical spare } \\
\text { parts (8.58\%); peralatan elektronik } \\
\text { dan onderdilnya/Electronic equipment } \\
\text { and its spare part, peralatan pemanas } \\
\text { dan pendingin serta onderdilnya/ } \\
\text { heating \& cooling equipment and its } \\
\text { spare parts ( } 8.24 \%) ; \text { bahan pewarna } \\
\text { /pigmen, cat dan perlengakapannya/ } \\
\text { dyes, paints and its accessories ( } 6.6 \%)\end{array}$ \\
\hline 2 & Norwegia & $\begin{array}{l}\text { Kayu olahan/ Woods product (6.4\%), } \\
\text { pakaian jadi/ clothing (14.3\%), tekstil/ } \\
\text { textiles (3.6\%), barang dari karet/ } \\
\text { rubber products (1.12\%), asam lemak/ } \\
\text { fatty acid (13.65\%), alat fotographi } \\
\text { dan optik/photography and optical } \\
\text { equipment (5.4\%), buah dan sayur } \\
\text { olahan/ fruit \& vegetables products } \\
\text { (3.61\%), mebel dari rotan/ rattan } \\
\text { furniture (10.5\%), mebel dari bahan } \\
\text { lainnya/ others furniture (10.9\%), } \\
\text { damar tiruan dan bahan dari plastik/ } \\
\text { artificial resins and plastics materials } \\
\text { (3.8\%), alaskaki/ footwear (4.9\%), } \\
\text { produk keramik/ ceramics products } \\
\text { (1.6\%), suku cadang mesin industri/ } \\
\text { spare parts industry (14.5\%), perikanan } \\
\text { (ubur-ubur, kepiting, ikan dan kerang- } \\
\text { kerangan)/ fisheries (jellyfish, crabs, } \\
\text { fish and shellfishes) 0.015\% }\end{array}$ & $\begin{array}{l}\text { Pupuk buatan/artificial fertilizers } \\
\text { ( } 23.2 \%), \text { peralatan listrik/electronics } \\
\text { equipment (15.7\%), peralatan handling } \\
\text { dan onderdilnya/handling equipment } \\
\text { and its spare part (10.4\%), material } \\
\text { dari karet/rubber material (9.9\%), } \\
\text { bubur kertas/pulp (7.3\%). }\end{array}$ \\
\hline 3 & Islandia & $\begin{array}{l}\text { barang dari karet/ rubber products } \\
(93.7 \%) \text { dan barang dari rotan/ rattan } \\
\text { produts }(4.4 \%) \text {. }\end{array}$ & $\begin{array}{l}\text { Pig iron, spiegelesein, sponge iron, } \\
\text { and ferro-alloys (86.1\%); animal oils } \\
\text { and fats (11.4\%); articles of apparel; } \\
\text { dan parts and accessories of the motor } \\
\text { vehicles (1.3\%). }\end{array}$ \\
\hline 4 & Liestentein & NIHIL & $\begin{array}{l}\text { bahan pewarna dan cat/dyes \& paints, } \\
\text { peralatan elektronik dan listrik/ } \\
\text { electronic \& electrical equipments, } \\
\text { logam/metal, bahan rajutan wool } \\
\text { buatan tangan dan pabrik/handmade } \\
\text { and factory wool products }\end{array}$ \\
\hline
\end{tabular}

Sumber : Diolah dari Buletin Statistik Perdagangan Luar Negeri Ekspor (Feb - 2011) dan Buletin Statistik Perdagangan Luar Negeri Impor (Feb-2011).

Source : $\quad$ Foreign Trade Statistical Bulletin - Export (Feb-2011), Foreign Trade Statistical Bulletin - Import (Feb-2011) (Processed). 
pasar negara EFTA, dengan brand yang dikenal oleh pasar EFTA. Ikan yang diimpor untuk tujuan tersebut catatannya harus mengikuti Standar International Trade Clasification System (SITC), bahan baku impor menjadi bahan olahan langsung untuk tujuan ekspor. Pada kasus ini Indonesia hanya mendapat jasa tenaga kerja, investasi, pajak dan pendapatan dari pengunaan beberapa input produksi. Ekspor tersebut nilainya tercatat sebagai barang ekspor Indonesia. Alternatif kedua investasi pada industri pengolahan hasil perikanan tersebut memanfaatkan bahan baku lokal dan diekspor ke pasar negara EFTA dengan brand yang dikenal oleh negara EFTA. Jenis ikan/produk olahan tersebut dicatat menurut SITC dan tercatat sebagai barang ekspor Indonesia.

b) Memberi kuota impor untuk jenis ikan segar/beku dan ikan olahan secara temporer sesuai keperluan. Kuota tersebut harus dirinci menurut jenis ikan dan jenis produk perikanan yang diperlukan dan mengikuti klasifikasi jenis barang dalam perdagangan yang didasarkan pada Harmonized System (HS) dan Standart International Trade Clasification System (SITC). Penerapan SITC ini (terhadap ikan segar/beku. Ikan olahan) dapat menelusuri asal ikan segar/beku, ikan olahan. Dengan demikian negara-negara EFTA diharapkan tidak mengirim ikan yang sumbernya berasal dari negara lain - (karena pasar Indonesia sangat potensial) - kecuali hasil penangkapan atau budidaya negara EFTA sendiri. Kuota impor ikan tersebut dapat dinegosiasikan dengan meminta akses pasar yang lebih besar kepada negara EFTA terhadap udang (segar/beku), ikan kaleng, Ikan segar beku (fillet dan loin) dengan brand Indonesia.

\section{Capacity Building}

Kerjasama dengan negara EFTA merupakan kesempatan bagi industri pengolahan ikan di Indonesia untuk menerapkan tata kelola industri perikanan yang bertanggungjawab, pada perikanan budidaya dan penangkapan ikan. Hal ini diperlukan agar produk perikanan Indonesia dapat diterima di negara-negara EFTA. Perbaikan tata kelola ini memerlukan beberapa tenaga technical adviser yang dapat melakukan supervisi kegiatan budidaya dan penangkapan ikan untuk mendampingi penerapan tata kelola perikanan yang baik (Code of Conduct for Responsible Fisheries-CCFRF dan Hazard Analytic Critical Control Point - HACCP) dan kebijakan negara EFTA lainnya yang terkait dengan perikanan dan mengikuti tata cara ekspor - impor hasil perikanan yang berlaku.

Bagi pemerintah dapat dimanfaatkan untuk perbaikan sistim dan cara pencatatan produksi budidaya, ekspor dan impor ikan mengikuti standar perdagangan umum dan standar kepabeaan dalam perdagangan antar negara, sehingga data dalam statistik perikanan Indonesia menjadi lebih akurat dan dapat dipertanggung jawabkan. Terkait dengan perdagangan Indonesia - EFTA catatan ekspor-impor Indonesia tersebut sesuai dengan catatan pada negara-negara EFTA. Pencatatan ini memerlukan harmonisasi istilah tentang jenis ikan, bentuk produk dan sebagainya.

Perbaikan ini memerlukan kerjasama untuk membangun infrastruktur pencatatan, termasuk pencatat statistik perikanan. Peningkatan kapasitas pencatatan statistik perikanan ini masih perlu dilakukan dengan menyempurnakan sumber pencatatan, waktu pencatatan dan sebagainya. Hal ini mencakup peningkatan kualitas sumberdaya manusia statistic perikanan. Upaya ini dapat dilakukan dengan peningkatan skill tenaga pencatat statistik perikanan dan keseragaman satuan dan sistim pencatatan; dan harmonisasi sistim kendali mutu, melalui pembinaan tenaga pengawasan.

\section{PENUTUP}

Kerjasama perdagangan Indonesia dan negara-negara EFTA mempunyai implikasi terhadap perkembangan industri perikanan di Indonesia. Indonesia saat ini menjadi 
pengekspor bahan mentah sedangkan Negara-negara EFTA mengekspor produk hasil industri ke Indonesia. Dalam rangka memperbaiki kualitas neraca perdagangan tersebut, maka sektor kelautan dan perikanan perlu melakukan negosiasi dengan negara EFTA, karena implikasi kerjasama tersebut akan berpengaruh pada akses pasar, rule of origin dan capacity building.

Dalam rangka memperluas akses pasar negosiasi harus dilakukan agar diperoleh peluang peningkatan ekspor ikan segar/beku, produk ikan kaleng (kepiting, ubur-ubur, udang) Indonesia ke masuk ke pasar negara-negara EFTA. Selain itu, negosiasi diharapkan dapat mendorong investasi Unit Pengolah Ikan EFTA di Indonesia untuk memenuhi permintaan pasar EFTA.

Memanfaatkan akses pasar untuk mendorong transfer teknologi kegiatan penangkapan ikan, budidaya dan pengolahan mengikuti aturan Internasional, agar produk perikanan Indonesia secara bertahap dapat diterima di negara-negara EFTA dan Uni Eropa.

Implementasi Rule of Origin dalam perikanan Indonesia harus dirintis untuk mendorong perbaikan sistim pencatatan produksi ikan, bahan baku ikan untuk pengolahan, dan ekspor-impor ikan. Implementasi ini mengikuti ketentuan Internasional (kepabeanan, Code HS dan SITC) untuk mencegah perdagangan ikan yang tidak fair dari EFTA ke Indonesia, karena hasil transhipment, hasil tangkapan illegal dan reekspor ke Indonesia.

Selain itu, kerjasama tersebut dapat dimanfaatkan untuk memperbaiki Capacity Building agar perikanan Indonesia dapat mengikuti kesepakatan internasional. Perbaikan Capacity Building dilakukan untuk: mendorong perbaikan statistik perikanan di Indonesia, yang meliputi: sistim pencatatan, infrastruktur pencatatan statistik perikanan, dan integrasi sistim statistik perikanan serta memperkuat kapasitas Sumberdaya Manusia statistik perikanan; peningkatan skill tenaga pencatat statistik perikanan dan keseragaman satuan dan sistim pencatatan; dan harmonisasi sistim kendali mutu, melalui pembinaan tenaga pengawasan.

\section{DAFTAR PUSTAKA}

Anonimous. 2011a. Buletin Statistik Perdagangan Luar Negeri - Ekspor. Feb 2011. BPS Jakarta.

. 2011b. Buletin Statistik Perdagangan Luar Negeri - Impor. Feb. 2011. BPS, Jakarta. . 2011c. Indonesia - EFTA : The 2nd Round of Negotiation Indonesia - EFTA Comprehensive Economic Partnership Agreement (IE-CEPA). Press Release. Kementerian Perdagangan. Jakarta.

. 2011d. What is in an EFTA Free Trade Agreement?. www.efta.int/free-trade/ learn-about-our-agreement.aspx. Download. 20 oktober 2011.

Björnsson, A.R. 2010. Iceland Seafood Market Report. Islandbanki Seafood Research. Reyjävik.

Clarke, S. 2009. Understanding China's Fish Trade and Traceability. TRAFFIC East Asia.

Lexmon, A. 2007. Norway Fishery Product Annual. Global Agriculture Information Network. Stockholm.

Rahardian, R., A.H. Purnomo, A. Zulham, Tajerin dan R. Hafsaridewi. 2011. Dampak Perjanjian Kerjasama Indonesia - EFTA Comprehensive Economic Partnership Agreement (IE-CEPA) terhadap Pembangunan Sektor Kelautan dan Perikanan Indonesia. BBRSEKP. Jakarta. 